\title{
Erratum to: "A Comparative Analysis of Methylation Status of Tumor Suppressor Genes in Paired Biopsy and Serum Samples from Cervical Cancer Patients among North Indian Population" [Russian Journal of Genetics, 52, 226 (2016)]
}

\author{
A. K. Jha ${ }^{a, c}$, V. Sharma ${ }^{a}$, M. Nikbakht ${ }^{a}$, V. Jain ${ }^{b}$, A. Sehgal ${ }^{d}$, N. Capalash ${ }^{a}$, and J. Kaur ${ }^{a}$ \\ ${ }^{a}$ Department of Biotechnology, Panjab University, Chandigarh, 160014 India \\ ${ }^{b}$ Department of Gynaecology, Mohan Dai Oswal Cancer Treatment and Research Foundation, Ludhiana, India \\ ${ }^{c}$ Department of Biotechnology, IMS Engineering College, Ghaziabad, 201009 India \\ ${ }^{d}$ Department of Gynaecology, Government Medical College and Hospital, Chandigarh, India \\ e-mail:jagsekhon@yahoo.com \\ Submitted June 14, 2016; accepted for publication June 14, 2016
}

DOI: $10.1134 / \mathrm{S} 1022795416080160$

In the title of the paper should read:

M. Nikbakht ${ }^{a, e}$

${ }^{e}$ Hematology Oncology and Stem Cell Transplantation Research Center, Tehran University of Medical Science, Tehran, Iran 